\title{
Mobility of Nanosized Cerium Dioxide and Polymeric Capsules in Quartz and Loamy Sands Saturated with Model and Natural Groundwaters
}

Revised and resubmitted to:

Water Research

June 20, 2013

\begin{abstract}
ADAMO RICCARDO PETOSA, CAROLIN ÖHL, FARAZ RAJPUT, and NATHALIE TUFENKJI
\end{abstract}

Department of Chemical Engineering, $M c$ Gill University, 3610 University St., Montreal, Quebec, Canada H3A 2B2 


\begin{abstract}
The environmental and health risks posed by emerging engineered nanoparticles (ENPs) released into aquatic environments are largely dependent on their aggregation, transport, and deposition behavior. Herein, laboratory-scale columns were used to examine the mobility of polyacrylic acid (PAA)-coated cerium dioxide nanoparticles $\left(n \mathrm{CeO}_{2}\right)$ and an analogous nanosized polymeric capsule $(n \mathrm{CAP})$ in water saturated quartz sand or loamy sand. The influence of solution ionic strength (IS) and cation type $\left(\mathrm{Na}^{+}, \mathrm{Ca}^{2+}\right.$, or $\left.\mathrm{Mg}^{2+}\right)$ on the transport potential of these ENPs was examined in both granular matrices and results were also compared to measurements obtained using a natural groundwater. ENP suspensions were characterized using dynamic light scattering and nanoparticle tracking analysis to establish aggregate size, and laser Doppler electrophoresis to determine ENP electrophoretic mobility. Regardless of IS, virtually all $n \mathrm{CeO}_{2}$ particles suspended in $\mathrm{NaNO}_{3}$ eluted from the quartz sand-packed columns. In contrast, heightened $n \mathrm{CeO}_{2}$ and $n \mathrm{CAP}$ particle retention and dynamic (time-dependent) transport behavior was observed with increasing concentrations of the divalent salts and in the presence of natural groundwater. Enhanced particle retention was also observed in loamy sand in comparison to the quartz sand, emphasizing the need to consider the nature of the aqueous matrix and granular medium in evaluating contamination risks associated with the release of ENPs in natural and engineered aquatic environments.
\end{abstract}

Keywords: cerium dioxide, nanoparticle, transport, polyacrylic acid, nanoparticle tracking analysis, loamy sand 


\section{Introduction}

Engineered nanoparticles (ENPs) exhibit appealing physicochemical properties that are absent in larger particles with equivalent chemical compositions (Auffan et al., 2009, Klaine et al., 2008). Consequently, ENPs of all types (e.g., carbon nanotubes, metals and metal oxides, semiconductors, polymers) are being incorporated into a growing number of consumer products. For example, nanosized titanium dioxide $\left(n \mathrm{TiO}_{2}\right)$ is employed in the production of sunscreens and paint, zinc oxide $(n \mathrm{ZnO})$ is used in cosmetics and solar cells, and iron oxides are incorporated into pigments and used in biological applications (Ju-Nam and Lead, 2008, Klaine et al., 2008). Comprehensive reviews of existing ENP types and their applications are available in the literature (Ju-Nam and Lead, 2008, Klaine et al., 2008). An inventory of consumer products containing ENPs has also been developed by the Woodrow Wilson International Center for Scholars (available at http://www.nanotechproject.org/).

Nanosized cerium dioxide $\left(n \mathrm{CeO}_{2}\right)$ is currently employed in several applications. It can serve as a polishing agent when manufacturing glass and can serve as a capacitor and semiconductor (Johnson and Park, 2012). Given that $n \mathrm{CeO}_{2}$ protects against the oxidative stress caused by reactive oxygen species, medical applications have also been described. These include the use of $n \mathrm{CeO}_{2}$ as an antioxidant to treat retinal disorders such as glaucoma (García et al., 2011). Since $n \mathrm{CeO}_{2}$ effectively absorbs ultraviolet radiation, it is used in the production of sunscreens and UV blocking agents (Cassee et al., 2011). Surface reactive properties also make $n \mathrm{CeO}_{2}$ a useful exhaust gas catalyst (Cassee et al., 2011, Van Hoecke et al., 2011).

Exposure to ENPs can occur at all stages of the particle lifecycle, including fabrication and processing, product usage and disposal (Wiesner and Bottero, 2007). Many $n \mathrm{CeO}_{2}$ applications are dispersive in nature, increasing the risk for exposure and heightened interactions 
with a variety of environmental media (Cassee et al., 2011). The release of $n \mathrm{CeO}_{2}$ particles employed as UV blocking agents or diesel fuel additives may threaten aquatic and sediment dwelling organisms (Van Hoecke et al., 2011). Beyond that, ENPs entering soil environments may reach groundwater aquifers, potentially contaminating drinking water supplies and causing unknown health, safety and environmental issues (Klaine et al., 2008). Once introduced into natural subsurface environments or engineered water treatment processes, particle aggregation, transport and deposition behavior will play a major role in determining $n \mathrm{CeO}_{2}$ fate, bioavailability and the likelihood for human exposure. Thus, a comprehensive understanding of $n \mathrm{CeO}_{2}$ transport and deposition behavior in water saturated granular systems is required for the protection of environmental and public health.

Well-controlled laboratory experiments using columns packed with different granular matrices can be useful for drawing links between collector (grain) properties and the mobility of released ENPs in water saturated granular environments (Kretzschmar et al., 1994, Petosa et al., 2010, Quevedo and Tufenkji, 2012). A number of studies have examined the transport and deposition of ENPs in quartz sand-packed columns, providing useful insights on the effects of environmental factors such as water chemistry, grain size, particle size, and porewater velocities on ENP mobility (Petosa et al., 2010). However, little is known regarding the transport and deposition of $n \mathrm{CeO}_{2}$ in water saturated granular environments (Li et al., 2011b, Liu et al., 2012).

Published $n \mathrm{CeO}_{2}$ transport studies have focused on the transport of bare particles suspended in monovalent salt solutions (namely, $\mathrm{NaCl}$ ). In considering the effect of $\mathrm{pH}$ and IS on $n \mathrm{CeO}_{2}$ deposition on sand, $\mathrm{Li}$ et al. observed increased particle retention under acidic conditions ( $\mathrm{pH}$ 3) and with increasing $\mathrm{NaCl}$ IS (Li et al., 2011b). Liu et al. investigated $n \mathrm{CeO}_{2}$ 
deposition in sand-packed columns and using a quartz crystal microbalance with dissipation (QCM-D). In $\mathrm{NaCl}\left(\mathrm{pH} 6.5\right.$ and 8), far more $n \mathrm{CeO}_{2}$ deposition was observed in the packed columns than on silica QCM-D sensors, likely due to physical straining as a result of ENP aggregation and heterogeneities on the quartz sand collectors. Heightened $n \mathrm{CeO}_{2}$ mobility in the packed columns was observed in the presence of organic matter (Liu et al., 2012). The transport of $n \mathrm{CeO}_{2}$ in the presence of divalent salt solutions (e.g., $\mathrm{CaCl}_{2}$ and $\mathrm{MgCl}_{2}$ ) and natural groundwater matrices has not been reported in the literature. Furthermore, studies investigating $n \mathrm{CeO}_{2}$ transport in granular matrices other than quartz sand are not available.

While the types of granular materials encountered in the natural subsurface environment can vary broadly (Kretzschmar et al., 1994), few studies have investigated the transport behavior of selected ENPs in media other than glass beads and quartz sand (Jaisi and Elimelech, 2009, Petosa et al., 2010). Previously, our group has shown that the retention of two different carboxyl-terminated quantum dots (QDs) and a carboxylated polystyrene latex nanoparticle can be enhanced by at least one order of magnitude in a loamy sand versus a quartz sand of comparable mean grain size (Quevedo and Tufenkji, 2012). Interestingly, the 3 different ENPs exhibit similar mobility in the quartz sand, but distinct transport behaviors in the loamy sand. This suggests that differences in the affinities of the polymer-coated ENPs for specific soil components can control their fate in subsurface environments. Jaisi and Elimelech investigated the transport of carboxyl-functionalized single-walled carbon nanotubes (SWCNTs) in columns packed with a complex granular matrix; namely, a sandy clay loam. Their study found SWCNT transport to be governed by physical straining, likely due to the combined effects of a very large $\mathrm{NP}$ aspect ratio, NP aggregation in solution and variability in soil particle size, porosity and permeability (Jaisi and Elimelech, 2009). 
The purpose of this work is to systematically investigate the mobility of a polyacrylic acid (PAA)-coated $n \mathrm{CeO}_{2}$ particle in water-saturated quartz sand and loamy sand matrices. Natural and artificial groundwaters are used to study the effect of electrolyte species and ionic strength (IS) on selected particle properties (i.e., aggregate size and surface potential) and transport potential. This study is the first to consider the effects of more complex granular materials and water chemistries on the transport behavior of $n \mathrm{CeO}_{2}$ in water saturated porous media. Moreover, the behavior of the PAA-coated $n \mathrm{CeO}_{2}$ is compared to that of analogous PAA-based nanocapsules ( $n$ CAPs) to assess whether both particle types exhibit similar transport potentials. The $n$ CAPs employed herein were designed to serve as water dispersible polymeric nanocapsules in agricultural applications, providing a further incentive to examine their behavior in model subsurface environments.

\section{Materials and Methods}

\subsection{Natural groundwater characterization}

Natural groundwater, originating from a domestic well in the township of North Glengarry, Ontario, was thoroughly characterized (methods and results are included in the Supporting Information, Table S1 and Figure S1).

\subsection{Granular collector surface characterization}

Quartz sand $\left(-50+70\right.$ mesh size, $d_{50}=256 \mu \mathrm{m}$, Sigma-Aldrich $)$ and loamy sand $\left(d_{50}=225 \mu \mathrm{m}\right)$ acquired at a $35 \mathrm{~cm}$ depth from an Agriculture and Agri-Food Canada (AAFC) farm plot located in St-Augustin-de-Desmaures, QC, were employed as granular materials in this study. An electrokinetic analyzer (Anton Paar Electro Kinetic Analyzer) was used to determine the surface 
(zeta) potential of the quartz sand for the experimental conditions considered herein (Supplementary Material, Table S2). Further collector characterization details are presented in the Supplementary Material and described elsewhere (Quevedo and Tufenkji, 2012).

\subsection{Nanoparticle suspension preparation}

Suspensions were prepared using polymer-coated $n \mathrm{CeO}_{2}$ (Batch Number: PB 54) and $n$ CAP (Batch Number: PB 67) powders (Vive Crop Protection). According to the manufacturer, the $n \mathrm{CeO}_{2}$ particles (cubic crystal structure) have a nominal size of 1-10 nm (TEM) and are coated with partially crosslinked PAA. The composition of the empty $n$ CAPs is analogous to that of the polymer-coating on the ceria particles (without the metal oxide core). The $n \mathrm{CeO}_{2}$ and $n \mathrm{CAP}$ synthesis is based on counter-ion induced polyelectrolyte collapse (Coulter et al., 2010). The PAA (polyelectrolyte) employed in producing the $n \mathrm{CeO}_{2}$ coating and $n \mathrm{CAP}$ particles has a $345 \mathrm{kDa}$ weight average molecular weight $\left(M_{w}\right)$. Furthermore, $M_{w}$ for the $n$ CAPs is $113 \mathrm{kDa}$ by gel permeation chromatography (GPC). Details regarding $n \mathrm{CeO}_{2}$ purity and preparation of ENP suspensions are provided in the Supplementary Material. Briefly, a particle concentration of 100 $\mathrm{mg} / \mathrm{L}$ was employed in all experiments. Experiments with $n \mathrm{CeO}_{2}$ were conducted in natural groundwater or in artificial electrolyte solutions at IS ranging from 0.1 to $1 \mathrm{M}$ sodium nitrate $\left(\mathrm{NaNO}_{3}\right), 0.33$ to $10 \mathrm{mM}$ calcium chloride $\left(\mathrm{CaCl}_{2}\right)$ and 0.33 to $12 \mathrm{mM}$ magnesium chloride $\left(\mathrm{MgCl}_{2}\right)$. The $n \mathrm{CAP}$ suspensions were prepared in $\mathrm{CaCl}_{2}(0.33$ to $20 \mathrm{mM})$ or natural groundwater. Suspension $\mathrm{pH}$ was stabilized using $1 \mathrm{mM}$ MOPS and adjusted to $\mathrm{pH} 8$ using $\mathrm{NaOH}$. 


\subsection{Nanoparticle characterization}

Particle electrophoretic mobilities (EPMs) were determined by laser Doppler electrophoresis (ZetaSizer Nano ZS, Malvern). All EPM measurements were performed at $25^{\circ} \mathrm{C}$, with an applied electrical field $(E)$ of $4.9 \pm 0.1 \mathrm{~V} / \mathrm{m}$. Particle hydrodynamic diameters were determined by DLS ( $\left.d_{\mathrm{DLS}}\right)$ using a Zetasizer Nano ZS (Malvern) and by nanoparticle tracking analysis (NTA, $\left.d_{\mathrm{NTA}}\right)($ Nanosight LM10+LM14, Wiltshire, UK). At least six independent replicate samples were analyzed using DLS and NTA.

\subsection{Nanoparticle transport and deposition studies}

ENP transport studies were performed using glass columns (16 mm inner diameter, GE Life Sciences) packed with quartz sand or loamy sand. Packed-bed porosities were 0.37 and 0.44 for the quartz and loamy sands, respectively. Prior to use, the quartz sand was prepared as previously described (Pelley and Tufenkji, 2008) and then soaked in background electrolyte for a minimum of 16 hours before wet packing into a glass column to a height of $14 \mathrm{~cm}$. Gentle vibration was used to avoid air entrapment within the packed bed, ensure uniform packing, and minimize any possible layering of the quartz sand. Prior to injecting the suspended ENPs into the quartz sand packed column, 10 pore volumes (PVs) of background electrolyte were pumped through the column.

Before use, the loamy sand was dried in an oven at $105^{\circ} \mathrm{C}$ for 8 hours. All clumps in the dried soil were gently crushed using a ceramic pestle. With some modifications, loamy sandpacked columns were prepared as previously described (Jaisi and Elimelech, 2009, Kretzschmar et al., 1997) to a height of $7 \mathrm{~cm}$. Briefly, loamy sand was dry-packed into a glass column. The column was then gently vibrated for $60 \mathrm{~s}$ to achieve uniform packing and purged with $\mathrm{CO}_{2}$ at 
low pressure (in the upward direction) for 20 minutes to improve water saturation. Next, the packed column was saturated with $20 \mathrm{mM} \mathrm{CaCl}_{2}$ solution (upward direction, $0.2 \mathrm{~mL} / \mathrm{min}$ flow rate) to stabilize the soil colloids. Once saturated, the column was further conditioned with 20 $\mathrm{mM} \mathrm{CaCl}_{2}$ at gradually increasing flow rates (stepwise from 0.2 to $1.3 \mathrm{~mL} / \mathrm{min}$ ) over the course of 1 hour. Next, an additional $40 \mathrm{PVs}$ of $\mathrm{CaCl}_{2}$ were added to the column, followed by $500 \mathrm{PVs}$ of background electrolyte (both in the upward direction, $1.3 \mathrm{~mL} / \mathrm{min}$ flow rate). Prior to the transport experiments, an additional 15 PVs of electrolyte were added (downward direction, 1.3 $\mathrm{mL} / \mathrm{min}$ ), followed by $1 \mathrm{PV}$ at $0.4 \mathrm{~mL} / \mathrm{min}$. Beyond equilibration, the experimental procedure was identical for quartz and loamy sand-packed columns. Consistent packing of both column types was confirmed using $10 \mathrm{mM} \mathrm{KNO}_{3}$ tracer experiments (data not shown).

For all column experiments, a $0.4 \mathrm{~mL} / \mathrm{min}$ flow rate (equivalent to a Darcy velocity of $2.86 \mathrm{~m} /$ day) was employed. At least 3 PVs of ENP suspensions were injected, followed by particle-free electrolyte. Influent $\left(C_{0}\right)$ and effluent $(C)$ particle concentrations were tracked online using a UV-visible spectrophotometer (Agilent 8453) equipped with a $1 \mathrm{~cm}$ flow-through cell. The $n \mathrm{CeO}_{2}$ particles were monitored at a wavelength of $300 \mathrm{~nm}$ in natural groundwater and divalent salts and at $320 \mathrm{~nm}$ in $\mathrm{NaNO}_{3}$. The $n \mathrm{CAPs}$ were monitored at $210 \mathrm{~nm}$. Very reproducible deposition data was obtained and all particle breakthrough curves presented are the average of at least 2 column experiments. At the highest $\mathrm{NaNO}_{3}$ IS (0.5 and $\left.1 \mathrm{M}\right), n \mathrm{CeO}_{2}$ breakthrough curves were determined by inductively coupled plasma mass spectrometry (ICPMS, Agilent 7500ce) using $\mathrm{HNO}_{3}$-digested effluent samples. 


\subsection{Interpretation of ENP Transport Behavior}

Particle transport behavior under the different experimental conditions was interpreted quantitatively using the particle attachment efficiency $(\alpha)$. All $\alpha$ values are calculated using the colloid filtration theory (Yao et al., 1971):

$$
\alpha=-\frac{2}{3} \frac{d_{50}}{(1-\varepsilon) L \eta_{0}} \ln \left(\frac{C}{C_{0}}\right)
$$

Here, $d_{50}$ is the mean collector grain diameter, $\varepsilon$ is the packed-bed porosity, $L$ is the packed-bed length and $C / C_{0}$ corresponds to the normalized particle concentration at the column effluent. The value of $C / C_{0}$ used in eq 1 was determined in two ways: (i) by averaging measured values between 1.8-2 PVs and (ii) by numerical integration of the area under each measured particle breakthrough curve. Values of the single-collector contact efficiency, $\eta_{0}$, were determined using the Tufenkji-Elimelech correlation (Tufenkji and Elimelech, 2004).

\section{Results and Discussion}

\subsection{Particle and quartz sand surface potential}

Under the experimental conditions used here ( $\mathrm{pH} 8)$, the EPMs of $n \mathrm{CeO}_{2}$ and $n$ CAP particles are negative (Table 1) due to the carboxylic acid groups present on the PAA chains. The experimentally determined point of zero charge $\left(\mathrm{pH}_{\text {zpc }}\right)$ for the $n \mathrm{CeO}_{2}$ and $n$ CAP particles is below $\mathrm{pH} 2$ (Figure S2). In the natural groundwater, the $n \mathrm{CeO}_{2}$ and $n$ CAP EPMs are -1.2 and $0.87 \mu \mathrm{mcmV}^{-1} \mathrm{~s}^{-1}$, respectively (Table 1). Our measurement for $n \mathrm{CeO}_{2}$ in groundwater is very comparable to that reported by Keller $e$ al. (Keller et al., 2010) for $n \mathrm{CeO}_{2}$ rods $(67 \times 8 \mathrm{~nm}$ nominal size, Meliorum Technologies): $-1.1 \mu \mathrm{mcmV}^{-1} \mathrm{~s}^{-1}$ in Santa Paula groundwater ( $\mathrm{pH}$ 7.9) and $-1.1 \mu \mathrm{mcmV}^{-1} \mathrm{~s}^{-1}$ in Santa Clara river water $(\mathrm{pH} 8.33)$. While there is no indication that the 
particles utilized by Keller et al. had a polymer coating such as the PAA utilized in the present study, the presence of organic carbon (considered to be a surrogate for natural organic matter) in the aquatic matrices was found to result in negative EPMs. Furthermore, increasing IS was found to result in less negative EPMs due to surface charge neutralization (Keller et al., 2010). As observed by Keller et al., $n \mathrm{CeO}_{2}$ EPMs become less negative with increasing IS in the monovalent and divalent salt solutions utilized herein (Table 1). EPM values for $n \mathrm{CeO}_{2}$ range from -2.7 to $-1.4 \mu \mathrm{mcmV}^{-1} \mathrm{~s}^{-1}$ when the solution IS varies between 0.33 to $10 \mathrm{mM} \mathrm{CaCl}_{2}$, from 2.7 to $-0.79 \mu \mathrm{mcmV}^{-1} \mathrm{~s}^{-1}$ when the solution IS varies between 0.33 to $12 \mathrm{mM} \mathrm{MgCl}_{2}$ and from 1.1 to $-0.57 \mu \mathrm{mcmV}^{-1} \mathrm{~s}^{-1}$ when the salt concentration is increased from 100 to $500 \mathrm{mM} \mathrm{NaNO}_{3}$ (Table 1). Likewise, $n$ CAP particle EPM decreases from -2.3 to $-1.0 \mu \mathrm{mcmV}^{-1} \mathrm{~s}^{-1}$ when the solution IS increases from 0.33 to $20 \mathrm{mM} \mathrm{CaCl}_{2}$ (Table 1). 
Table 1. Measured

hydrodynamic diameter and

electrophoretic mobility (EPM)

for $n \mathrm{CeO} 2$ and $n \mathrm{CAP}$ particles*

\begin{tabular}{|c|c|c|c|c|c|c|c|c|c|c|}
\hline article & $\begin{array}{c}\text { lonic } \\
\text { Strength } \\
\text { (mM } \\
\text { NaNO3) }\end{array}$ & $\begin{array}{c}\text { Ionic } \\
\text { Strength } \\
(\mathrm{mM} \\
\mathrm{CaCl})\end{array}$ & $\begin{array}{c}\text { Ionic } \\
\text { Strength } \\
(\mathrm{mM} \\
\mathrm{MgCl} 2)\end{array}$ & $\begin{array}{c}\text { Natural } \\
\text { Groundwater }\end{array}$ & $\begin{array}{l}d D L S \\
(n m)\end{array}$ & $\begin{array}{l}\text { PDI } \\
\text { (for } \\
\text { DLS) }\end{array}$ & $\begin{array}{l}d N T A \\
(n m)\end{array}$ & $\begin{array}{c}\text { EPM } \\
(\mu \mathrm{mcmV}- \\
1 \mathrm{~s}-1)\end{array}$ & $\begin{array}{c}\alpha D L S, \\
\text { quartz } \\
\text { sand }\end{array}$ & $\begin{array}{c}\alpha \mathrm{DLS}, \\
\text { loamy } \\
\text { sand }\end{array}$ \\
\hline
\end{tabular}

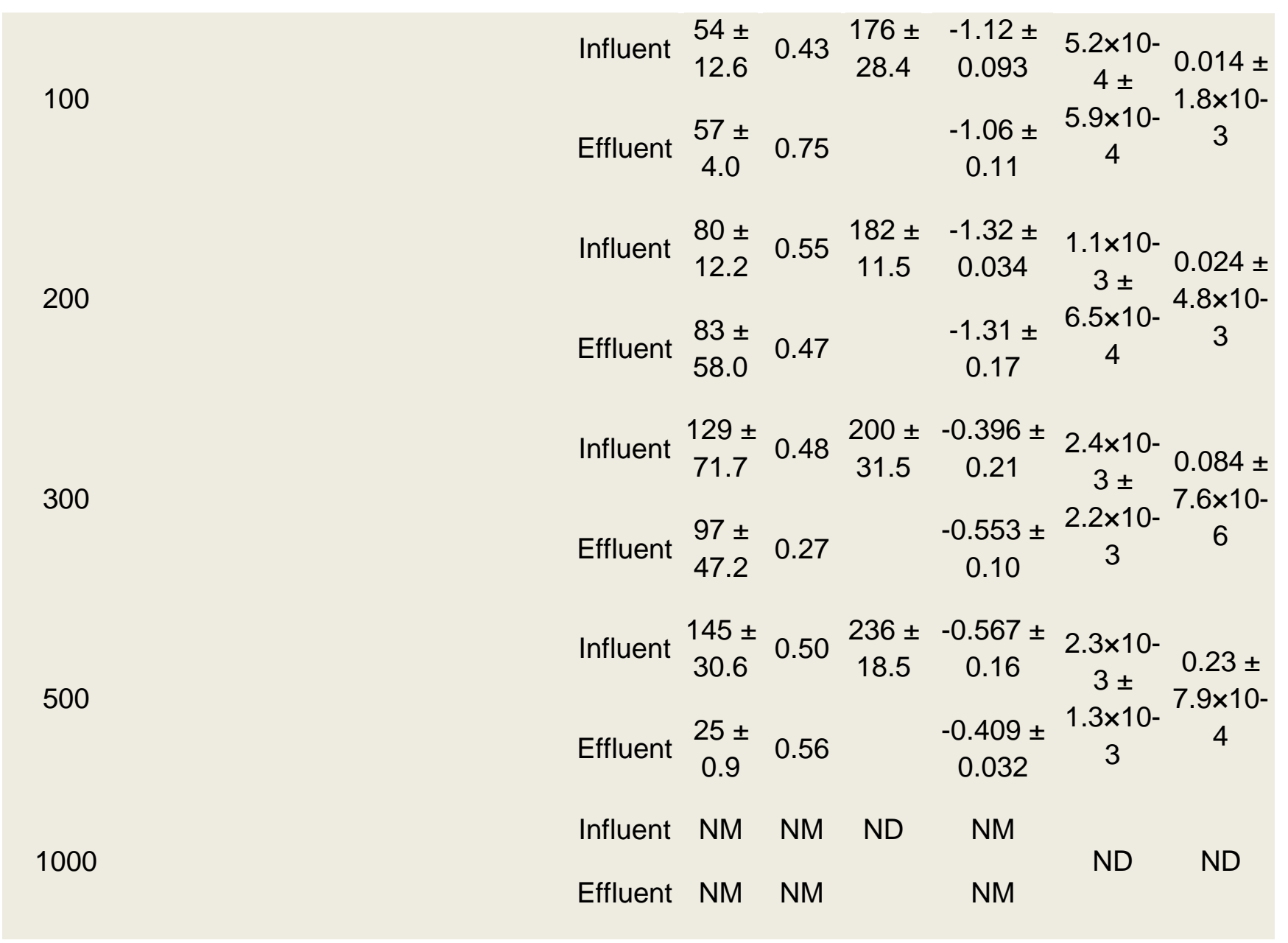

nCeO2

0.33

3.3

6.7

10

\begin{tabular}{|c|c|c|c|c|c|c|}
\hline Influent & $\begin{array}{l}137 \pm \\
11.5\end{array}$ & 0.34 & $\begin{array}{l}157 \pm \\
16.9\end{array}$ & $\begin{array}{l}-2.70 \pm \\
0.21\end{array}$ & $\begin{array}{c}7.3 \times 10- \\
5 \pm\end{array}$ & $\begin{array}{c}7.3 \times 10- \\
3 \pm\end{array}$ \\
\hline Effluent & $\begin{array}{l}107 \pm \\
11.2\end{array}$ & 0.33 & & $\begin{array}{l}-2.85 \pm \\
0.22\end{array}$ & $\begin{array}{c}1.4 \times 10 \\
4\end{array}$ & $\begin{array}{c}1.3 \times 10 \\
3\end{array}$ \\
\hline fluent & $\begin{array}{l}140 \pm \\
1.8\end{array}$ & 0.20 & $\begin{array}{l}90 \pm \\
9.0\end{array}$ & $\begin{array}{l}-1.90 \pm \\
0.087\end{array}$ & $\begin{array}{c}6.6 \times 10- \\
4 \pm\end{array}$ & $0.052 \pm$ \\
\hline ffluent & $\begin{array}{l}136 \pm \\
5.8\end{array}$ & 0.20 & & $\begin{array}{l}-1.88 \pm \\
0.22\end{array}$ & $\begin{array}{c}2.5 \times 10- \\
4\end{array}$ & 3 \\
\hline ffluent & $\begin{array}{l}193 \pm \\
8.1\end{array}$ & 0.11 & $\begin{array}{l}106 \pm \\
5.9\end{array}$ & $\begin{array}{l}-1.44 \pm \\
0.027\end{array}$ & $\begin{array}{l}0.014 \pm \\
5.3 \times 10-\end{array}$ & $\begin{array}{c}0.13 \pm \\
5.9 \times 10\end{array}$ \\
\hline ffluent & $\begin{array}{l}191 \pm \\
6.8\end{array}$ & 0.12 & & $\begin{array}{l}-1.34 \pm \\
0.023\end{array}$ & 4 & 3 \\
\hline fluent & $\begin{array}{l}565 \pm \\
48.4\end{array}$ & 0.32 & $\begin{array}{l}153 \pm \\
15.9\end{array}$ & $\begin{array}{l}-1.43 \pm \\
0.066\end{array}$ & $0.049 \pm$ & $0.50 \pm$ \\
\hline ffluent & $\begin{array}{l}487 \pm \\
53.1\end{array}$ & 0.29 & & $\begin{array}{l}-1.40 \pm \\
0.033\end{array}$ & 0.011 & 0.47 \\
\hline fluent & $\begin{array}{l}712 \pm \\
65.3\end{array}$ & 0.92 & $\begin{array}{l}128 \pm \\
10.7\end{array}$ & $\begin{array}{l}-1.37 \pm \\
0.025\end{array}$ & $0.17+$ & \\
\hline nt & $\begin{array}{l}166= \\
16.8\end{array}$ & 0.84 & & $\begin{array}{l}-1.33 \pm \\
0.046\end{array}$ & 0.12 & \\
\hline
\end{tabular}

$\begin{array}{ccccccc}\text { Influent } & \begin{array}{cccc}81 \pm \\ 4.7\end{array} & 0.66 & 152 \pm & -2.65 \pm & 1.5 \times 10- & \text { ND } \\ & & & 8.2 & 0.15 & 4 \pm & \end{array}$ 


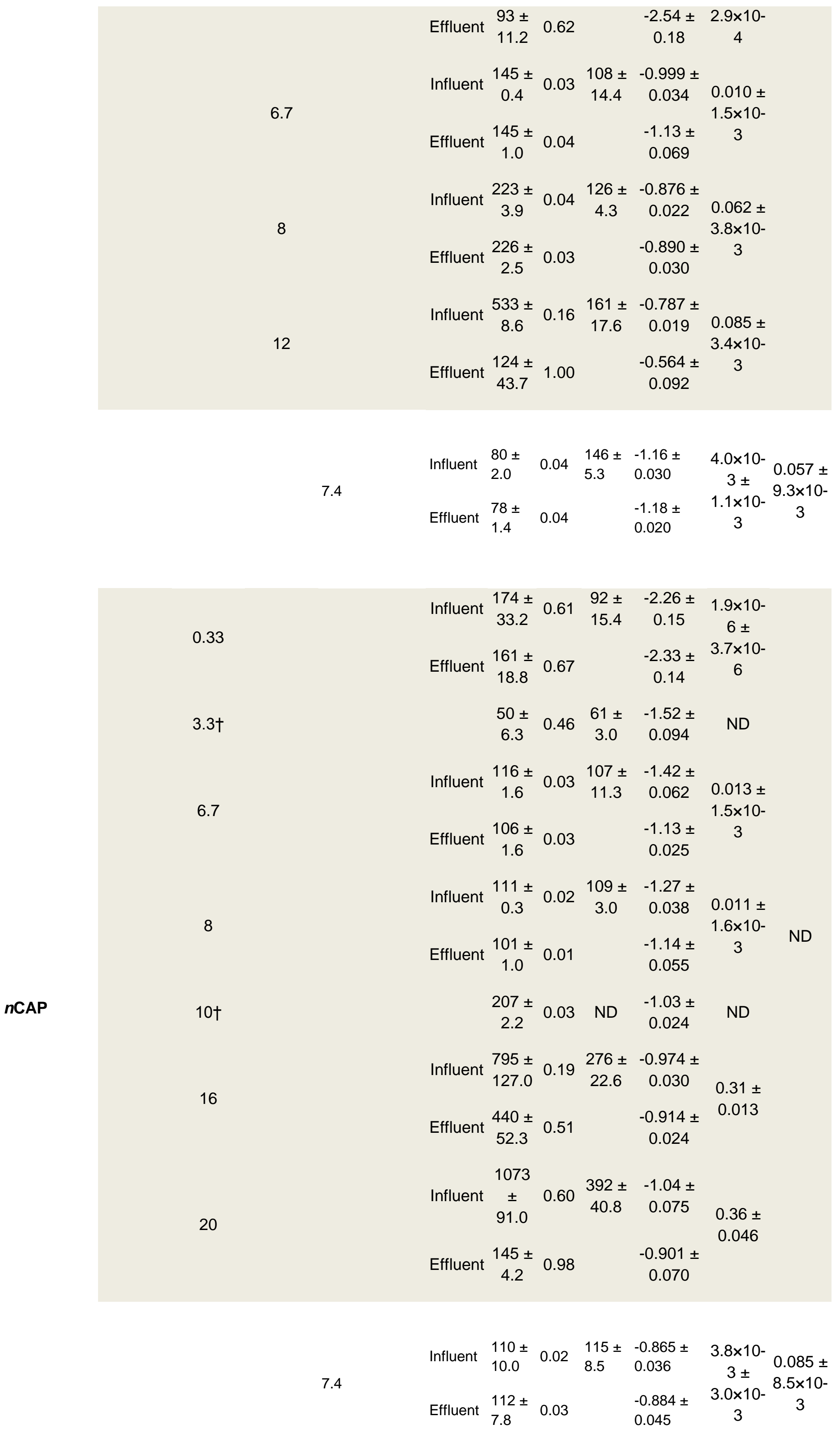

$\mathrm{NM}=$ This value is not reported as reproducible measurements could not be obtained. 
$\mathrm{ND}=$ Values were not determined experimentally.

* All values represent means $\pm 95 \% \mathrm{Cl}$. Effluent values determined following quartz sand column experiments.

† Column experiments were not performed. 
The observed decrease in surface potential with increasing solution IS can be directly attributed to electrical double-layer compression and the screening of particle surface charge with increasing salt concentration. Compared to monovalent cations, divalent cations such as $\mathrm{Ca}^{2+}$ and $\mathrm{Mg}^{2+}$ are far more effective in masking surface charge (Hunter, 2001). While divalent cation screening efficiency results in rapid $n \mathrm{CeO}_{2}$ destabilization at IS $>10 \mathrm{mM} \mathrm{CaCl}$ or $12 \mathrm{mM}$ $\mathrm{MgCl}_{2}$, stable suspensions can be observed in $\mathrm{NaNO}_{3}$ at IS $>500 \mathrm{mM}$. As previously suggested by Chen and Elimelech, the decrease in EPM observed in the presence of $\mathrm{CaCl}_{2}$ and $\mathrm{MgCl}_{2}$ may be due to the binding of $\mathrm{Ca}^{2+}$ and $\mathrm{Mg}^{2+}$ to carboxylic acid groups (Chen and Elimelech, 2007).

The zeta-potential of the quartz sand in natural and artificial groundwater matrices $(\mathrm{pH}$ 8) was evaluated from the measured steaming potentials. Negative zeta-potentials are observed over the range of experimental conditions, and the absolute value of the zeta-potential decreases with increasing IS, and in the presence of divalent cations. Details are provided in the Supplementary Information (Table S2).

\subsection{Particle size}

In this study, ENP hydrodynamic diameters were determined using DLS $\left(d_{\mathrm{DL} S}\right)$ and NTA $\left(d_{\mathrm{NTA}}\right)$. The average size of $n \mathrm{CeO}_{2}$ particles in suspensions injected into the packed columns generally increases with increasing IS of $\mathrm{NaNO}_{3}, \mathrm{CaCl}_{2}$, or $\mathrm{MgCl}_{2}$ (Table 1, "influent" values). Measured values of $d_{\mathrm{DLS}}$ range from 137 to $712 \mathrm{~nm}$ (in 0.33 and $10 \mathrm{mM} \mathrm{CaCl}_{2}$, respectively), 81 to $533 \mathrm{~nm}$ (in 0.33 and $12 \mathrm{mM} \mathrm{MgCl}_{2}$, respectively) and 54 to $145 \mathrm{~nm}$ (in 100 and $500 \mathrm{mM} \mathrm{NaNO}$, respectively). The observed increase in $n \mathrm{CeO}_{2}$ aggregate size with increasing IS is in qualitative agreement with the DLVO theory of colloid stability (Derjaguin and Landau, 1941, Verwey and Overbeek, 1948). Namely, reduced particle surface potentials at 
higher IS result in decreased repulsive interaction energies between two approaching particle surfaces, giving rise to greater particle aggregation. At a given IS, $n \mathrm{CeO}_{2}$ aggregate sizes are larger in $\mathrm{CaCl}_{2}$ than $\mathrm{MgCl}_{2}$ (Table 1). Furthermore, for the purpose of the transport studies, "stable" $n \mathrm{CeO}_{2}$ suspensions could be prepared at IS of up to $12 \mathrm{mM} \mathrm{MgCl}$; however "stable" $n \mathrm{CeO}_{2}$ suspensions could not be prepared at IS $>10 \mathrm{mM} \mathrm{CaCl}_{2}$ (suspension stability was verified by monitoring sedimentation using UV-visible spectrophotometry and changes in hydrodynamic diameter using DLS; data not shown). The aforementioned findings suggest that $\mathrm{Ca}^{2+}$ is more effective in masking surface charge (and compressing the polymer chains) than $\mathrm{Mg}^{2+}$. This is in agreement with previous studies considering boron nanoparticle aggregation and deposition (Liu, 2009) and fullerene ( $\left.\mathrm{C}_{60}\right)$ aggregation (Chen and Elimelech, 2007). Both these studies found $\mathrm{Ca}^{2+}$ to be more effective than $\mathrm{Mg}^{2+}$ in screening surface charge. Finally, the measured $d_{\mathrm{DLS}}$ of $n \mathrm{CeO}_{2}$ in natural groundwater is $80 \mathrm{~nm}$ (Table 1).

In addition to the particle sizing measurements performed using DLS, particle sizes for the suspensions injected into the packed columns were also measured using NTA (Table $1, d_{\text {NTA }}$ “influent" values). Under selected conditions, values of $d_{\mathrm{NTA}}$ are comparable to $d_{\mathrm{DLS}}$, as noted for $n$ CAPs in groundwater $\left(d_{\mathrm{DLS}}=110 \mathrm{~nm}\right.$, while $\left.d_{\mathrm{NTA}}=115 \mathrm{~nm}\right)$. However, significant discrepancies between the two sets of measurements are at times apparent, especially at higher IS of the divalent salts, where $d_{\mathrm{DLS}}$ are larger than the measured $d_{\mathrm{NTA}}$. DLS determined sizes for polydisperse suspensions will be biased by the larger aggregates present, as Rayleigh scattering is proportional to particle diameter raised to the $6^{\text {th }}$ power (Filella et al., 1997). While NTA determined sizes are also dependant on light scattering, the masking of smaller particles in the presence of larger aggregates is less important (Domingos et al., 2009a), resulting in smaller reported diameters. Furthermore, NTA has an upper size limit on the order of $1 \mu \mathrm{m}$, further 
decreasing reported sizes in the presence of large aggregates (Carr et al., 2008). Thus, whereas $d_{\mathrm{DLS}}$ for $n$ CAPs in $20 \mathrm{mM} \mathrm{CaCl}_{2}$ is $1073 \mathrm{~nm}$ (in part due to high polydispersity), $d_{\mathrm{NTA}}$ at this condition is $392 \mathrm{~nm}$ (Table 1). It should also be noted that the NTA has a lower size limit of 30 $\mathrm{nm}$ that is dependent on the refractive index of the nanoparticles being observed (Filipe et al., 2010). This may affect the determined sizes when examining particles with very small nominal diameters (such as the 1-10 nm particles employed herein).

The largest particle aggregates are encountered at the highest IS tested; yet, increasing the concentration of the divalent salt beyond $0.33 \mathrm{mM}$ appears to result in decreased aggregate sizes in certain cases. This trend, apparent in the measured $n$ CAP hydrodynamic sizes $\left(d_{\mathrm{DLS}}\right)$, as well as the $d_{\mathrm{NTA}}$ for $n \mathrm{CeO}_{2}$ and $n$ CAP particles suspended in divalent salts, suggests that different mechanisms may be influencing the extent of particle aggregation. While this trend is not apparent in the $d_{\mathrm{DLS}}$ values determined for $n \mathrm{CeO}_{2}$, higher $d_{\mathrm{DLS}}$ standard deviations (as indicated by the $95 \%$ confidence interval) and heightened suspension polydispersity, as indicated by the polydispersity index $(\mathrm{PDI})$, are encountered at the lowest $(0.33 \mathrm{mM})$ divalent salt IS when compared to IS of 3.3 or $6.7 \mathrm{mM}$ (Table 1). The standard deviations and PDI values observed suggest that a wider range of aggregate sizes are present at $0.33 \mathrm{mM}$ than at 3.3 and $6.7 \mathrm{mM}$, where suspensions appear to be less polydisperse. The $d_{\mathrm{DLS}}$ of the $n \mathrm{CAP}$ particle at the higher IS of 3.3 and $6.7 \mathrm{mM} \mathrm{CaCl}_{2}$ (50 and $116 \mathrm{~nm}$, respectively) are also significantly smaller than the particle size at $0.33 \mathrm{mM}(174 \mathrm{~nm})$, where heightened polydispersity is again encountered. As observed with $n \mathrm{CeO}_{2}, n$ CAP size increases at the highest IS (Table 1).

It is known that PAA can adopt different conformations based on surrounding solvent characteristics such as the ion species present, $\mathrm{pH}$ and IS (Turro and Arora, 1986). Whereas a coiled, more compressed conformation may be favored when carboxylic acid groups are 
protonated (due to hydrogen bonding between monomers), deprotonation will result in electrostatic repulsion within the PAA backbone, favoring a stretched conformation (Sarkar and Somasundaran, 2004). Likewise, while repulsive interactions between charged carboxyl groups will result in extended PAA conformations at lower IS, the addition of counterions (i.e. increased IS) will screen the charge, enabling the polyelectrolyte chains to collapse (Coulter et al., 2010). Partial crosslinking of the PAA chains by the manufacturer also likely affects the extent of PAA expansion and compression.

The fact that PAA can adopt different conformations is likely responsible for the larger particle sizes or heightened polydispersity observed at the lowest $(0.33 \mathrm{mM})$ divalent salt IS, as a stretched polymer conformation is favored. Under these conditions, the extended polymer chains contribute to the larger particle size detected. Increasing the IS leads to decreased repulsion within the PAA polymer chains, enabling them to become more coiled, compressed and uniform (as polymer chains are fastened in place by the divalent counterions). This corresponds to the decrease in recorded size and/or PDI as IS increases to 3.3 or $6.7 \mathrm{mM}$. Decreased electrostatic repulsion and reduced steric effects (due to polymer compression) will ultimately favor particle aggregation, resulting in the formation of the larger aggregates observed at the highest salt concentrations examined. The influence of solution IS on the thickness of nanoparticle polymer coatings is currently the focus of ongoing research in our group.

While $n$ CAP composition is analogous to that of the $n \mathrm{CeO}_{2}$ polymer coating, $n \mathrm{CAP}$ aggregate sizes are generally smaller than $n \mathrm{CeO}_{2}$ at a given $\mathrm{CaCl}_{2}$ IS (Table 1). For instance, the $d_{\mathrm{DLS}}$ of $n \mathrm{CeO}_{2}$ in $8 \mathrm{mM} \mathrm{CaCl}_{2}$ is $565 \mathrm{~nm}$, whereas $n \mathrm{CAP}$ aggregates at this IS measure $111 \mathrm{~nm}$. Due to the heightened $n \mathrm{CeO}_{2}$ aggregation observed, stable ceria suspensions can not be prepared at IS above $10 \mathrm{mM} \mathrm{CaCl}_{2}$. On the other hand, $n \mathrm{CAP}$ suspensions can be prepared at IS as high 
as $20 \mathrm{mM} \mathrm{CaCl}_{2}$. The greater $n \mathrm{CeO}_{2}$ aggregation suggests that the polymer coating on this particle may not be completely uniform and, hence, may not provide as effective electrosteric stabilization as that observed for the $n$ CAP. The $\mathrm{pH}_{\text {zpc }}$ for bare $n \mathrm{CeO}_{2}$ is reported to be $\mathrm{pH} 7.6$ (Li et al., 2011a). As previously observed with natural organic matter adsorbed on the surface of metal oxide particles (Domingos et al., 2009b, Kretzschmar et al., 1997), the PAA coating in this study significantly alters the particle surface potential, as the $\mathrm{pH}_{\text {zpc }}$ for the $n \mathrm{CeO}_{2}$ particles employed is below $\mathrm{pH} 2$ (Figure S2). Given that all experiments are conducted at $\mathrm{pH} 8(\sim \mathrm{pH}$ for the $n \mathrm{CeO}_{2}$ core), any exposed $n \mathrm{CeO}_{2}$ core material carries virtually no surface charge. The $n \mathrm{CeO}_{2}$ particles with partially exposed cores will be more likely to aggregate, as weaker repulsive forces are encountered at the uncovered sites. This phenomenon is not an issue for the $n$ CAPs, as they consist solely of PAA.

\subsection{Transport and deposition of $n \mathrm{Ce}_{2}$ and $n C A P$}

The primary aim of this study is to investigate $n \mathrm{CeO}_{2}$ and $n \mathrm{CAP}$ deposition behavior in quartz sand and loamy sand-packed columns. ENP transport studies were conducted using natural groundwater or artificial solutions of either monovalent $\left(\mathrm{NaNO}_{3}\right)$ or divalent $\left(\mathrm{CaCl}_{2}, \mathrm{MgCl}_{2}\right)$ salts. Given the aforementioned discrepancies between the two particle sizing techniques, both $d_{\mathrm{DLS}}$ and $d_{\mathrm{NTA}}$ values were considered in calculating the single-collector contact efficiency $\left(\eta_{0}\right)$, resulting in two estimates for the ENP attachment efficiency, $\alpha$ (using eq 1). Furthermore, for each transport experiment, the normalized particle concentration at the column effluent $\left(C / C_{0}\right)$ was evaluated using two approaches: (i) averaging values between 1.8-2 PVs and, (ii) by numerical integration of the area under each breakthrough curve. Consequently, for each experimental condition, four distinct $\alpha$ values were obtained. Regardless of the sizing technique 
and manner in which $C / C_{0}$ is determined, the calculated $\alpha$ values are within a factor of $1-3$ times for the vast majority of experimental conditions (Tables S3 and S4). For simplicity, attachment efficiencies discussed herein and presented in Table 1 are those obtained using $d_{\mathrm{DLS}}$ and $C / C_{0}$ values evaluated by numerical integration of the particle breakthrough curves.

\subsubsection{Transport and deposition in the presence of monovalent salts}

Regardless of $\left[\mathrm{NaNO}_{3}\right]$ (IS ranging from 0.1 to $1 \mathrm{M}$ ), virtually all $n \mathrm{CeO}_{2}$ particles elute from the quartz sand-packed columns (Figure 1a). Even at 1 M IS, only $20 \%$ retention is observed. Given that particle and collector surfaces are negatively charged at $\mathrm{pH} 8$, lower absolute surface potentials at higher IS should render deposition more favorable, while heightened aggregation could result in the physical straining of particles within the packed column. Although particle EPM decreases (-1.1 to $\left.-0.57 \mu \mathrm{mcmV}^{-1} \mathrm{~s}^{-1}\right)$ and aggregate size increases (54 to $145 \mathrm{~nm}$ ) when the IS increases from 100 to $500 \mathrm{mM} \mathrm{NaNO}_{3}$ (Table 1), near complete particle elution is still observed over this range of IS. Nonetheless, comparison of $n \mathrm{CeO}_{2}$ particle sizes in column influent and effluent suspensions provides support for a mechanism of particle straining (Table 1). Physical straining occurs when large aggregates become entrapped in the narrower pores between collector surfaces (Bradford et al., 2002, Shen et al., 2008). As the pores clog, incoming particles become entrapped, resulting in decreased elution. The data in Table 1 show that, at IS $>200 \mathrm{mM} \mathrm{NaNO}_{3}, n \mathrm{CeO}_{2}$ particle sizes in the column effluent are considerably smaller than those measured in the influent suspensions. This suggests that the larger aggregates formed at the higher salt concentrations are preferentially retained in the granular matrix (likely by physical straining). 

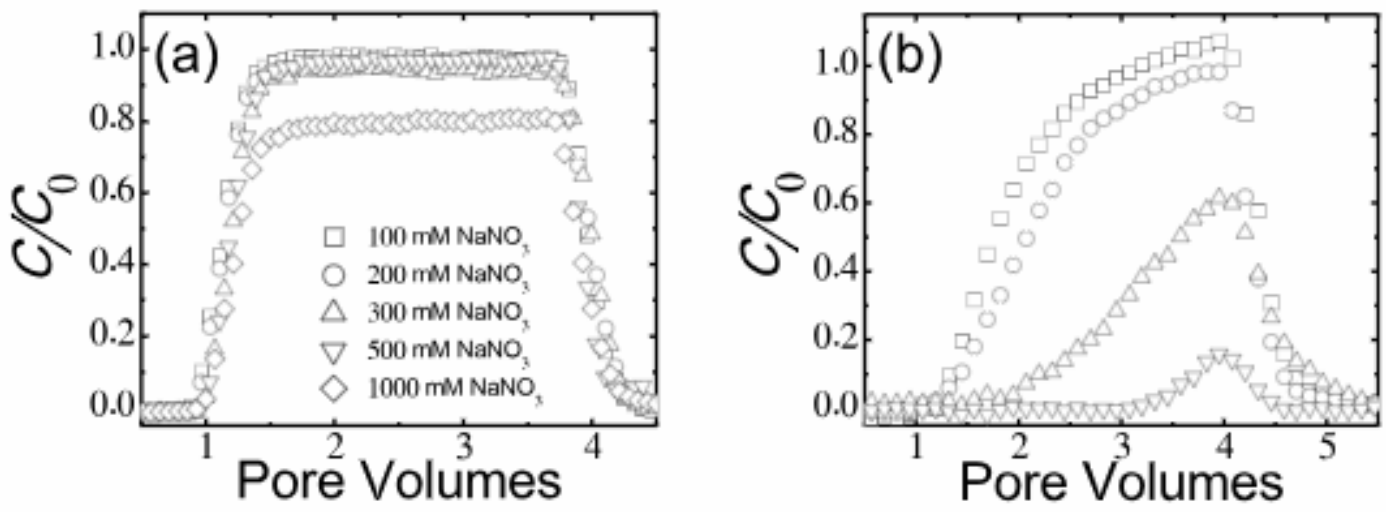

Fig. $1-n \mathrm{CeO}_{2}$ breakthrough curves in $\mathrm{NaNO}_{3}$. Transport experiments were performed in (a) quartz and (b) loamy sand-packed columns using $100 \mathrm{mg} / \mathrm{L} n \mathrm{CeO}_{2}$ suspensions ( $\mathrm{pH} \mathrm{8)}$.

Significantly more retention is reported in a recent study by $\mathrm{Li}$ et al. (Li et al., 2011b) investigating bare $n \mathrm{CeO}_{2}$ transport and deposition in $45 \mathrm{~cm}$ sand-packed columns. Although the particles used in their study were suspended in monovalent $\mathrm{NaCl}$, significant particle retention occurred at $1 \mathrm{mM}$ IS under more favorable deposition conditions $(\mathrm{pH} 3)$ and at 10 mM IS under unfavorable deposition conditions ( $\mathrm{pH} 6$ and $\mathrm{pH}$ 9). While the longer columns employed by Li et al. would naturally result in greater particle retention, they also made use of coarser quartz sand $(d=717 \mu \mathrm{m})$ and a faster $20 \mathrm{~mL} / \mathrm{min}$ flow rate (Li et al., 2011b). Hence, the observed discrepancies between the two studies are likely due to the PAA coating on the Vive Crop Protection ${ }^{\mathrm{TM}}$ particles. Such a coating can result in the electrosteric stabilization of the particles (Elimelech et al., 1995, Franchi and O'Melia, 2003), resulting in heightened particle transport.

Liu et al. (Liu et al., 2012) also report very high retention of bare $n \mathrm{CeO}_{2}$ in quartz sandpacked columns $(10 \mathrm{mM} \mathrm{NaCl})$. While their columns were similar in length and contained collector grains of similar composition and size (sand sifted through 250-300 $\mu \mathrm{m}$ sieves) to those used herein, only $4.3 \%$ of $n \mathrm{CeO}_{2}$ was found to elute at $\mathrm{pH} 8.5$ in their study. The $n \mathrm{CeO}_{2}$ employed by Liu et al. had a $\mathrm{pH}_{2 \mathrm{pc}}$ of 6.8 , rendering deposition unfavorable at $\mathrm{pH}$ 8.5. The 
authors suggest that heightened retention under unfavorable conditions may have resulted from surface roughness and chemical heterogeneities on the collector surfaces (Liu et al., 2012). In the presence of organic matter (e.g., humic acid), they observed enhanced $n \mathrm{CeO}_{2}$ stability and mobility (in $1 \mathrm{mM} \mathrm{NaCl}, \mathrm{pH}$ 6.5), likely due to electrosteric effects of the adsorbed humic acid. Adding 1, 3 or $6 \mathrm{mg} / \mathrm{L}$ humic acid, resulted in increased particle elution. The heightened particle elution observed in the presence of stabilizing humic acid (Liu et al., 2012) is in better agreement with the polymer-coated $n \mathrm{CeO}_{2}$ transport observed in the present study (in $\mathrm{NaNO}_{3}$ ). When $n \mathrm{CeO}_{2}$ particles suspended in $\mathrm{NaNO}_{3}$ are added to loamy sand-packed columns, greater particle retention is observed, with $\alpha$ values as high as 0.23 at $500 \mathrm{mM}$ IS (Table 1 ). In contrast to the steady-state behavior observed in the quartz sand columns (Figure 1a), particle elution is dynamic and increases over time in the loamy sand (Figure 1b). The heightened retention observed in loamy sand is likely due to increased favorable deposition sites within the packed bed when compared to quartz sand. These additional sites likely result from the presence of clays within the loamy sand (Quevedo and Tufenkji, 2012). While albite $\left(\mathrm{pH}_{\mathrm{zpc} \approx 5.9)}\right.$ ) and orthoclase $\left(\mathrm{pH}_{\mathrm{zp}} \approx 1\right)$ in the clay fraction present unfavorable conditions for $n \mathrm{CeO}_{2}$ and $n \mathrm{CAP}$ retention at $\mathrm{pH} 8$, allophane $\left(\mathrm{pH}_{\mathrm{zpc}} \approx 7.8\right)$ in the clay fraction may provide additional positively charged sites onto which negatively charged ENPs can "favorably" deposit (Quevedo and Tufenkji, 2012, Sposito, 1989). Although the Fe content of the loamy sand was not quantified, the presence of Fe was confirmed by EDS. If iron oxides are present in the loamy sand, they would also play an important role in the favorable deposition of the negatively charged ENPs (Ryan and Elimelech, 1996).

The number of favorable deposition sites in the packed bed increases with increasing IS due to the charge masking effect of the $\mathrm{Na}^{+}$counterions. This leads to increased retention with 
increasing IS within the loamy sand (Figure 1b). The dynamic elution behavior observed is indicative of a blocking effect within the column (Liu et al., 1995, Ryan and Elimelech, 1996). As favorable deposition sites become occupied, fewer sites remain for incoming particles. Thus, the incoming particles are repelled by deposited particles with similar surface potentials and less likely to find an available deposition site. Electrostatic repulsion and steric interactions may also prevent incoming particles from depositing onto sites adjacent to previously deposited particles (Ko and Elimelech, 2000). These conditions result in increased particle elution over time. Although the size of $n \mathrm{CeO}_{2}$ particles in the column effluent were not measured for experiments conducted with loamy sand packed columns, it is very likely that physical straining also contributes to the retention of particles in this system. The extent of physical straining is strongly influenced by the particle to grain size ratio (Tufenkji et al., 2004); because the mean sizes of the two sands are comparable, there is a strong possibility that straining is also playing a role in the loamy sand.

\subsubsection{Transport and deposition in the presence of divalent salts}

In the presence of divalent salts, the attachment efficiency increases over several orders of magnitude with increasing IS (Table 1). For $n \mathrm{CeO}_{2}$ suspended in $\mathrm{CaCl}_{2}(0.33$ to $10 \mathrm{mM})$, determined $\alpha$ values range from $7.3 \times 10^{-5}$ to 0.17 in quartz sand, and $7.3 \times 10^{-3}$ to 0.50 in loamy sand (Table 1). Likewise, $n \mathrm{CeO}_{2}$ attachment efficiency in quartz sand increases from $1.5 \times 10^{-4}$ to 0.085 when the IS of $\mathrm{MgCl}_{2}$ is increased from 0.33 to $12 \mathrm{mM}$ (Table 1). While dynamic (timedependent) particle transport behavior is encountered in both granular materials, less retention is observed in the quartz sand at any given IS. 
In quartz sand, significant particle retention is observed at $\mathrm{CaCl}_{2} \mathrm{IS} \geq 6.7 \mathrm{mM}$ (Figure 2a). At $\mathrm{pH} 8$, the $n \mathrm{CeO}_{2}$ and quartz sand have a negative surface potential, rendering deposition unfavorable. Nonetheless, the particle and collector surface potentials observed at $6.7 \mathrm{mM}$ $\mathrm{CaCl}_{2}$ are less negative than at $0.33 \mathrm{mM} \mathrm{CaCl}_{2}$ (Table S2). Such decreased surface potentials increase the likelihood of deposition as electrostatic particle-surface interactions are less repulsive (Derjaguin and Landau, 1941, Elimelech and O'Melia, 1990a, b, Verwey and Overbeek, 1948). Furthermore, as discussed previously, higher $\left[\mathrm{CaCl}_{2}\right]$ will decrease electrostatic repulsion within the PAA coating, favoring a compressed conformation. This will result in decreased steric repulsion, further favoring particle deposition. Slightly more than $20 \%$ of particles suspended in $6.7 \mathrm{mM} \mathrm{CaCl}_{2}$ are retained by the quartz sand, with elution increasing over time (due to the aforementioned blocking phenomenon). On the other hand, $75 \%$ of the $n \mathrm{CeO}_{2}$ is retained in loamy sand at the same IS (Figure $2 \mathrm{~b}$ ).
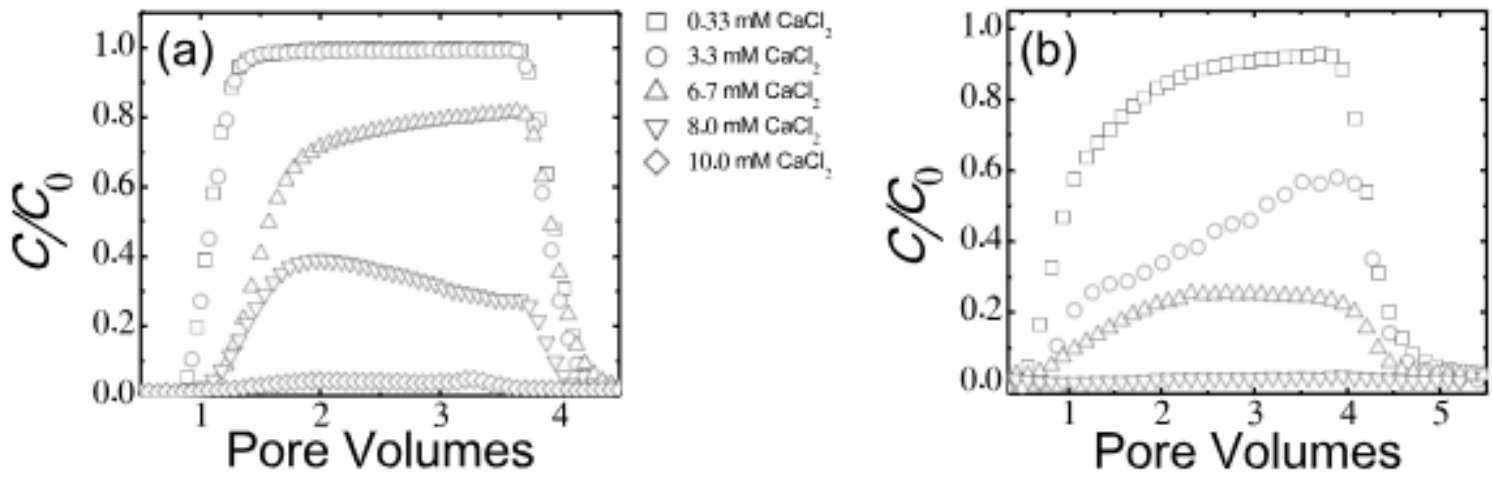

Fig. $2-n \mathrm{CeO}_{2}$ breakthrough curves in $\mathrm{CaCl}_{2}$. Transport experiments were performed in (a) quartz and (b) loamy sand-packed columns using $100 \mathrm{mg} / \mathrm{L} n \mathrm{CeO}_{2}$ suspensions (pH 8).

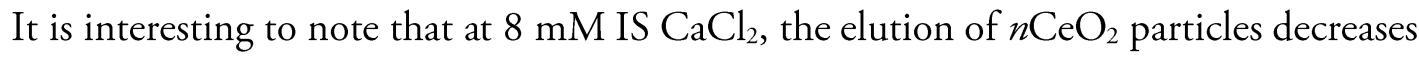
with time (Figure 2a). At this condition, the $n \mathrm{CeO}_{2}$ particles are larger than those observed at lower $\left[\mathrm{CaCl}_{2}\right](565 \mathrm{~nm}$ versus $193 \mathrm{~nm}$ at $6.7 \mathrm{mM})$, suggesting the decreased particle elution with time could be a result of physical straining. Here, influent and effluent values of $d_{\mathrm{DLS}}$ for 
$n \mathrm{CeO}_{2}$ are generally comparable at the lower concentrations of $\mathrm{CaCl}_{2}$ (Table 1 ), indicating that particle aggregation or particle straining do not occur during the transport experiment. Yet, at higher $\mathrm{CaCl}_{2}$ concentrations, $n \mathrm{CeO}_{2}$ particle sizes in the column effluent are consistently smaller than influent values, suggesting that physical straining occurs. In $8 \mathrm{mM} \mathrm{CaCl}_{2}$, the effluent $d_{\mathrm{DLS}}$ $(487 \mathrm{~nm})$ is significantly smaller than the influent $d_{\mathrm{DLS}}(565 \mathrm{~nm})$. This is even more apparent in $10 \mathrm{mM} \mathrm{CaCl}$, where the influent $d_{\mathrm{DLS}}(712 \mathrm{~nm})$ is considerably larger than the effluent diameter $(166 \mathrm{~nm})$. While blocking of the most favorable deposition sites is likely occurring, physical straining is likely responsible for the observed decreased particle elution with time at higher IS. As observed in $\mathrm{CaCl}_{2}, n \mathrm{CeO}_{2}$ particles suspended in $\mathrm{MgCl}_{2}$ exhibit heightened deposition at higher IS in quartz sand (Figure 3). However, contrary to the physical straining observed at 8 and $10 \mathrm{mM} \mathrm{CaCl}_{2}$ (Figure 2a), blocking is apparent at $\mathrm{MgCl}_{2}$ IS ranging from 6.7 to $12 \mathrm{mM}$, with particle elution increasing over time (Figure 3). The distinct dynamic behaviors observed likely result from differences in the aggregate sizes encountered in the two divalent salts. Overall, aggregates in the $\mathrm{MgCl}_{2}$ solutions are smaller than in $\mathrm{CaCl}_{2}$ at a given IS. At $8 \mathrm{mM} \mathrm{IS}$, the $n \mathrm{CeO}_{2} d_{\mathrm{DLS}}$ in $\mathrm{MgCl}_{2}$ is $223 \mathrm{~nm}$, which is significantly smaller than the $565 \mathrm{~nm} d_{\mathrm{DLS}}$ measured in $8 \mathrm{mM} \mathrm{CaCl}_{2}$ (Table 1). It appears the smaller aggregates in $\mathrm{MgCl}_{2}$ do not result in the significant physical straining observed at higher $\mathrm{CaCl}_{2}$ IS. Consequently, once favorable deposition sites become occupied, heightened particle elution is observed. At the highest $\mathrm{MgCl}_{2}$ IS tested $(12 \mathrm{mM})$, aggregate sizes are much larger $(533 \mathrm{~nm})$. Furthermore, effluent $d_{\mathrm{DLS}}$ are much smaller than influent $d_{\mathrm{DLS}}$, suggesting that the largest aggregates are preferentially retained (Table 1). The fact that this does not result in significant physical straining (based on the slope of the breakthrough curves, Figure 3) suggests there are likely fewer large aggregates in the 
$\mathrm{MgCl}_{2}$ solutions. Although the largest may become entrapped in the packed bed, their retention does not appear to result in the extensive pore clogging and physical straining observed in $\mathrm{CaCl}_{2}$.

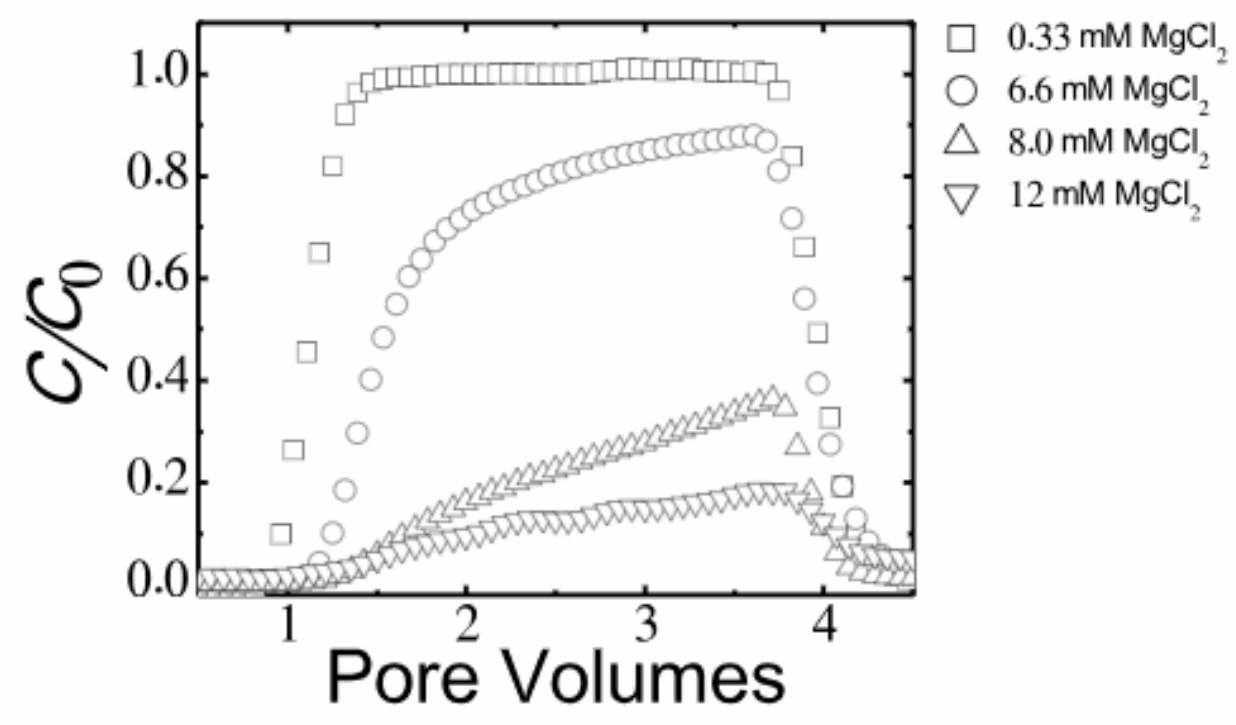

Fig. $3-n \mathrm{CeO}_{2}$ breakthrough curves in $\mathrm{MgCl}_{2}$. Transport studies were performed in quartz sand using $100 \mathrm{mg} / \mathrm{L} n \mathrm{CeO}_{2}$ suspensions ( $\mathrm{pH} 8$ ).

The transport and deposition behavior of the $n$ CAPs, consisting of the same PAA polymer that is present on the $n \mathrm{CeO}_{2}$ particle surface, was also examined under selected conditions. The water dispersible $n$ CAPs are among various prototypes developed by Vive Crop Protection to potentially deliver active agents that protect crops and heighten yields, while decreasing the use of potentially harmful pesticides. Before such capsules can be applied to agricultural soils on a large scale, their behavior in model subsurface environments must be evaluated.

Similar to the trends observed for $n \mathrm{CeO}_{2}$, the $n \mathrm{CAP}$ breakthrough curves also exhibit increased retention with increasing $\left[\mathrm{CaCl}_{2}\right]$ in quartz sand (Figure 4). Moreover, increased $n$ CAP elution with time (indicative of particle blocking) is observed at 6.7 and $8.0 \mathrm{mM} \mathrm{CaCl}_{2}$. As observed with $n \mathrm{CeO}_{2}$, the $d_{\mathrm{DLS}}$ of the $n \mathrm{CAP}$ in column effluent suspensions is smaller than the measured hydrodynamic diameter of the influent suspensions at higher $\mathrm{CaCl}_{2}$ IS (Table 1). 
For example, at $16 \mathrm{mM}$ IS, the influent $d_{\mathrm{DLS}}(795 \mathrm{~nm})$ is nearly twice as large as the size of the $n$ CAPs in the column effluent. These data suggest that larger aggregates are preferentially retained within the granular medium. $n$ CAP attachment efficiencies are comparable to the $n \mathrm{CeO}_{2} \alpha$ values observed in 6.7 and $8 \mathrm{mM} \mathrm{CaCl}_{2}$ and in natural groundwater (Table 1), suggesting the two particle types have a similar transport potential.

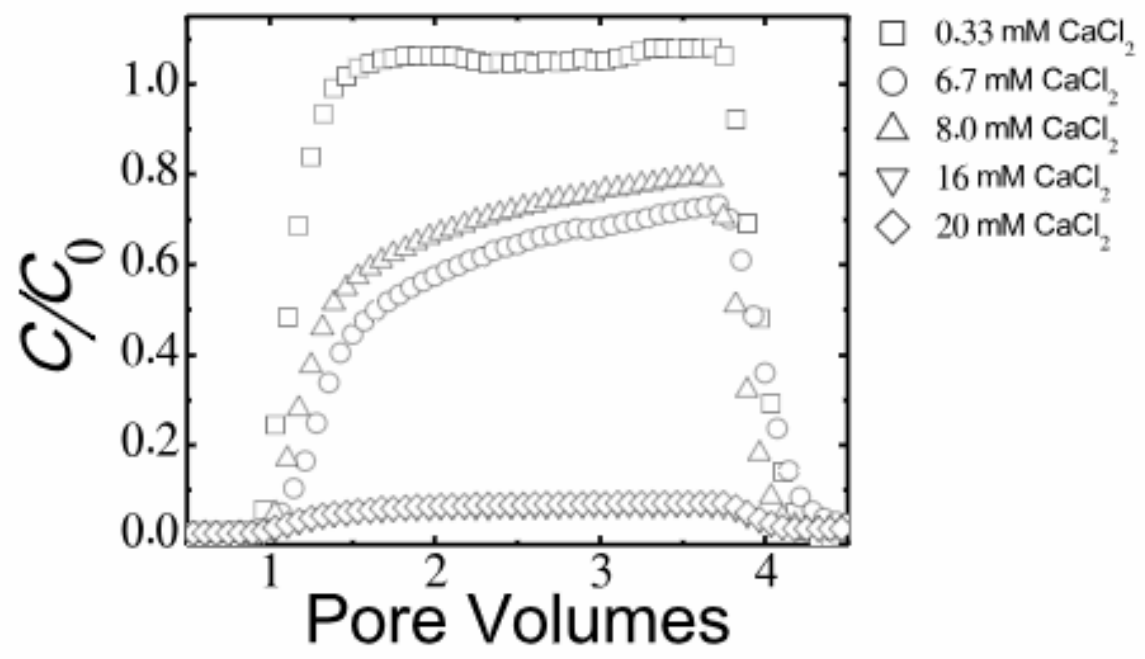

Figure 4. Representative breakthrough curves for $n$ CAP particles in quartz sand-packed columns $\left(0.33-20 \mathrm{mM} \mathrm{CaCl}_{2}, \mathrm{pH}\right)$.

\subsubsection{Transport and deposition of ENPs suspended in a natural groundwater}

In quartz sand, $n \mathrm{CeO}_{2}$ and $n \mathrm{CAP}$ particles suspended in natural groundwater demonstrate significant transport potential, with particle elution gradually approaching 80 and $100 \%$, respectively (Figure 5a). While the attachment efficiency for both particle types is approximately $4 \times 10^{-3}$ in quartz sand, calculated $\alpha$ values are an order of magnitude larger in loamy sand (Table 1). A previous study conducted in our laboratory also showed QD and carboxylated polystyrene latex nanoparticle retention in loamy sand to be heightened by an order of magnitude compared to particle behavior in quartz sand (Quevedo and Tufenkji, 2012). The shapes of the particle breakthrough curves from experiments conducted using the loamy sand 
columns and natural groundwater indicate that particle blocking contributes to the overall $n \mathrm{CeO}_{2}$ and $n \mathrm{CAP}$ transport behavior (Figure $5 \mathrm{~b}$ ). As observed in quartz sand, the transport potential for both particles in loamy sand is very similar, with $\alpha$ values of 0.057 and 0.085 for $n \mathrm{CeO}_{2}$ and $n \mathrm{CAP}$, respectively. In contrast, our group previously observed that the retention behaviors of two carboxy-terminated QDs and a carboxylated polystyrene latex nanoparticle were distinct in loamy sand (Quevedo and Tufenkji, 2012). Although the coatings of all three particle types in the aforementioned study possessed carboxyl functional groups, their surfaces consisted of different polymers. Consequently, variations in transport behavior likely resulted from differences in polymer-coating affinities for specific loamy sand components. Such apparent differences were not encountered in the present study, as $n$ CAP particle composition is analogous to the $n \mathrm{CeO}_{2}$ polymer coating.
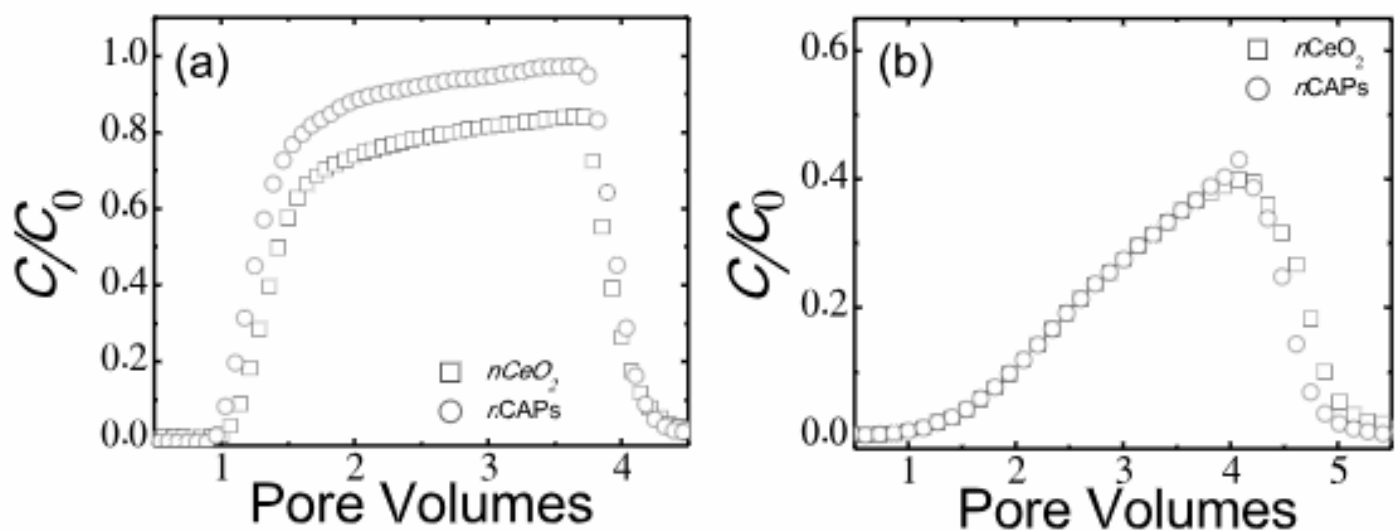

Figure 5. Representative breakthrough curves for $n \mathrm{CAP}$ and $n \mathrm{CeO}_{2}$ particles suspended in natural groundwater and injected into (a) quartz sand and (b) loamy sand-packed columns ( $\mathrm{pH} 8)$.

The natural groundwater used in this study has a total IS of $7.4 \mathrm{mM}$, of which $\mathrm{Ca}^{2+}$ and $\mathrm{Mg}^{2+}$ account for $5 \mathrm{mM}\left(3.6 \mathrm{mM} \mathrm{Ca}^{2+}\right.$ and $\left.1.4 \mathrm{mM} \mathrm{Mg}^{2+}\right)$. Thus, it is of interest to compare the transport of the ENPs in the artificial matrices having comparable concentrations of the divalent cations. In quartz and loamy sands, $n \mathrm{CeO}_{2}$ attachment efficiencies observed in natural groundwater are higher than those observed in $3.3 \mathrm{mM} \mathrm{CaCl}_{2}$ and lower than those observed at 
$6.7 \mathrm{mM} \mathrm{CaCl}_{2}$. These findings correspond to the fact that divalent cations account for $5 \mathrm{mM}$ of the total $7.4 \mathrm{mM}$ groundwater IS. Likewise, in quartz sand, the $n \mathrm{CAP} \alpha$ value observed in natural groundwater is lower than that observed in $6.7 \mathrm{mM} \mathrm{CaCl}_{2}$.

\subsubsection{Summary of the transport behavior of PAA-coated ENPs}

One of the aims of this study is to compare $n \mathrm{CeO}_{2}$ and $n \mathrm{CAP}$ transport behavior. When plotting $n \mathrm{CeO}_{2}$ and $n \mathrm{CAP}$ particle attachment efficiencies in quartz sand as a function of $\mathrm{CaCl}_{2}$ IS (Figure 6), it is evident that $n$ CAP $\alpha$ values are smaller at $0.33 \mathrm{mM}$ and comparable to $n \mathrm{CeO}_{2}$ at 6.7 and $8 \mathrm{mM}$. Beyond the current study, previous work by this group considered the transport behavior of $n \mathrm{TiO}_{2}, n \mathrm{ZnO}$ and $\mathrm{CdTe}$ QDs with the same PAA-derived surface coating (Petosa et al., 2012, Quevedo and Tufenkji, 2012). As in the current study, we also observed that $\alpha$ increases with increasing IS for the other PAA-coated ENPs. In Figure 6, we have included previously reported $\alpha$ values for experiments conducted with the PAA-coated $n \mathrm{TiO}_{2}$, $n \mathrm{ZnO}$ and $\mathrm{CdTe} \mathrm{QDs}$ in $\mathrm{CaCl}_{2}$ and quartz sand. The attachment efficiencies for these other ENPs are generally higher than those observed with the $n$ CAP (Figure 6). At $8 \mathrm{mM} \mathrm{CaCl}_{2}$, the $n$ CAP $\alpha$ in quartz sand is 0.011 , orders of magnitude smaller than the $\alpha$ values previously observed for $n \mathrm{TiO}_{2}(\alpha=0.63)$ and $n \mathrm{ZnO}(\alpha=1.1)$ (Petosa et al., 2012). Likewise, $\alpha=0.69$ for QDs in $5 \mathrm{mM} \mathrm{CaCl}_{2}$ (Quevedo and Tufenkji, 2012), which is higher than the $n \mathrm{CAP}$ attachment efficiency at $20 \mathrm{mM}$ IS. The data in Figure 6 demonstrate that while the transport behavior for the various particle types is not identical (potentially due to partially exposed cores), the $n$ CAP transport behavior is most comparable to that of the $n \mathrm{CeO}_{2}$ particles. Note that while $n \mathrm{CAP}, n \mathrm{CeO}_{2}$ and $n \mathrm{ZnO}$ studies were conducted at $\mathrm{pH} 8, n \mathrm{TiO}_{2}$ and $\mathrm{QD}$ studies were conducted at $\mathrm{pH} 7$. 


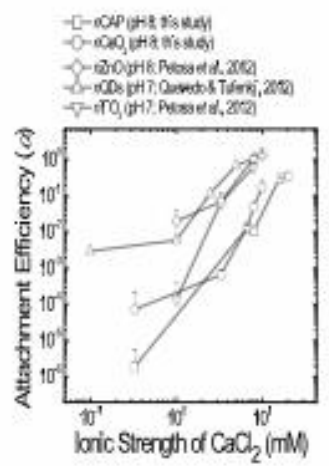

Figure 6. Attachment efficiency $(\alpha)$ as a function of $\mathrm{CaCl}_{2}$ IS for $n \mathrm{CAP}, n \mathrm{CeO}_{2}, \mathrm{QD}, n \mathrm{TiO}_{2}$ and $n \mathrm{ZnO}$ particles in quartz sand-packed columns. 
While the current study improves our understanding of $n \mathrm{CeO}_{2}$ transport and deposition behavior in saturated granular environments, there are inherent limitations that should be noted. Firstly, soil characteristics (e.g., hydraulic conductivity, mineralogical and organic matter content) are location and depth dependent. Consequently, ENP affinity for various soil types and in different soil horizons will vary significantly. Nonetheless, the current study identifies particular environmental characteristics that result in enhanced ENP mobility (e.g., sandy soils, lower salt concentrations). Furthermore, while different natural and artificial groundwater matrices are employed, all experiments are conducted at $\mathrm{pH}$ 8. Geographical variations in groundwater $\mathrm{pH}$ will affect ENP deposition as changes in particle and collector surface potential, colloidal stability, aggregate size and interactions with soil components (e.g., humic substances) will occur (Navarro et al., 2009, Quevedo and Tufenkji, 2012). Finally, the loamy sand packedcolumns employed are not extracted as undisturbed cores. Still, by conducting well-controlled experiments using two different granular materials, we obtain useful insight into the influence of collector grain properties and water chemistry on ENP transport and retention. 


\section{Conclusions}

This study clearly demonstrates that it is necessary to consider aquatic matrix composition and soil type in evaluating ENP contamination risks. Overall, enhanced $n \mathrm{CeO}_{2}$ particle retention is encountered at higher divalent salt $\left(\mathrm{CaCl}_{2}\right.$ and $\left.\mathrm{MgCl}_{2}\right)$ concentrations and in loamy sand. Namely, it is evident that:

- while virtually all $n \mathrm{CeO}_{2}$ particles suspended in $\left[\mathrm{NaNO}_{3}\right] \leq 500 \mathrm{mM}$ elute from the quartz sand-packed columns, heightened particle retention and dynamic behavior (blocking) is observed in loamy sand.

- $n \mathrm{CeO}_{2}$ attachment efficiency increases over several orders of magnitude within a narrow range of divalent salt IS $\left(0.33-10 \mathrm{mM} \mathrm{CaCl}_{2}\right.$ and $\left.1-12 \mathrm{mM} \mathrm{MgCl}_{2}\right)$. While dynamic behavior (blocking and physical straining) is encountered in both granular materials, lower retention is observed in quartz sand at any given IS.

- $n \mathrm{CeO}_{2}$ and $n \mathrm{CAP}$ attachment efficiencies for particles suspended in natural groundwater are an order of magnitude higher in loamy sand than in quartz sand.

- the enhanced retention observed in loamy sand may partially be due to the presence of favorable deposition sites on clays such as allophane, and metal oxides such as iron oxide.

The aforementioned findings indicate that specific environmental conditions (e.g., sandy soils, decreased ionic strength, and decreased divalent salt concentrations) are more conducive to heightened particle mobility. Finally, the transport potential of the model polymeric capsule $(n \mathrm{CAP})$ is generally greater than that of various PAA-coated ENPs previously tested and most comparable to the $n \mathrm{CeO}_{2}$ used in the present study. 


\section{Acknowledgements}

This research was supported by NSERC, the Ministère du développement économique, innovation et exportation du Québec, the CRC Program, Environment Canada, Vive Crop Protection, and the CFI. ARP was funded by NSERC (PGS) and a MEDA. FR was partially supported by a McGill SURE award. The authors also thank Ivan Quevedo for helpful discussions, F. Duquette-Murphy and K. J. Wilkinson (U. Montreal) for NTA assistance and A. Tessier (Concordia) for ICP-MS assistance. 


\section{References}

Auffan, M., Rose, J., Bottero, J.-Y., Lowry, G.V., Jolivet, J.-P. and Wiesner, M.R., 2009. Towards a definition of inorganic nanoparticles from an environmental, health and safety perspective. Nature Nanotechnology 4, 634-641.

Bradford, S.A., Yates, S.R., Bettahar, M. and Simunek, J., 2002. Physical factors affecting the transport and fate of colloids in saturated porous media. Water Resources Research 38 (12), 631-6312.

Carr, B., Malloy, A. and Warren, J., 2008. Nanoparticle tracking analysis. Innovations in Pharmaceutical Technology (26), 38-40.

Cassee, F.R., Van Balen, E.C., Singh, C., Green, D., Muijser, H., Weinstein, J. and Dreher, K., 2011. Exposure, health and ecological effects review of engineered nanoscale cerium and cerium oxide associated with its use as a fuel additive. Critical Reviews in Toxicology 41 (3), 213-229.

Chen, K.L. and Elimelech, M., 2007. Influence of humic acid on the aggregation kinetics of fullerene $\left(\mathrm{C}_{60}\right)$ nanoparticles in monovalent and divalent electrolyte solutions. Journal of Colloid and Interface Science 309 (1), 126-134.

Coulter, M.M., Dinglasan, J.A., Goh, J.B., Nair, S., Anderson, D.J. and Dong, V.M., 2010. Preparing waterdispersed palladium nanoparticles via polyelectrolyte nanoreactors. Chemical Science 1 (6), 772-775.

Derjaguin, B.V. and Landau, L.D., 1941. Theory of stability of strongly charged lyophobic sols and the adhesion of strongly charged particles in solutions of electrolytes. Acta Physicochimica URSS 14, 633-662.

Domingos, R.F., Baalousha, M.A., Ju-Nam, Y., Reid, M.M., Tufenkji, N., Lead, J.R., Leppard, G.G. and Wilkinson, K.J., 2009a. Characterizing manufactured nanoparticles in the environment: Multimethod determination of particle sizes. Environmental Science \& Technology 43 (19), 7277-7284.

Domingos, R.F., Tufenkji, N. and Wilkinson, K.J., 2009b. Aggregation of titanium dioxide nanoparticles: Role of a fulvic acid. Environmental Science and Technology 43 (5), 1282-1286.

Elimelech, M., Gregory, J., Jia, X. and Williams, R.A., 1995. Particle Deposition and Aggregation: Measurement, Modeling, and Simulation, Butterworth-Heinemann, Oxford.

Elimelech, M. and O'Melia, C.R., 1990a. Effect of particle size on collision efficiency in the deposition of brownian particles with electrostatic energy barriers. Langmuir 6 (6), 1153-1163.

Elimelech, M. and O'Melia, C.R., 1990b. Kinetics of deposition of colloidal particles in porous media. Environmental Science and Technology 24 (10), 1528-1536.

Filella, M., Zhang, J., Newman, M.E. and Buffle, J., 1997. Analytical applications of photon correlation spectroscopy for size distribution measurements of natural colloidal suspensions: Capabilities and limitations. Colloids and Surfaces A: Physicochemical and Engineering Aspects 120 (1-3), 27-46. 
Filipe, V., Hawe, A. and Jiskoot, W., 2010. Critical evaluation of nanoparticle tracking analysis (NTA) by

NanoSight for the measurement of nanoparticles and protein aggregates. Pharmaceutical Research 27 (5), 796-810.

Franchi, A. and O'Melia, C.R., 2003. Effects of natural organic matter and solution chemistry on the deposition and reentrainment of colloids in porous media. Environmental Science and Technology 37 (6), 1122-1129.

García, A., Espinosa, R., Delgado, L., Casals, E., González, E., Puntes, V., Barata, C., Font, X. and Sánchez, A., 2011. Acute toxicity of cerium oxide, titanium oxide and iron oxide nanoparticles using standardized tests.

Desalination 269 (1-3), 136-141.

Hunter, R.J., 2001. Foundations of Colloid Science, Oxford University Press Inc., New York.

Jaisi, D.P. and Elimelech, M., 2009. Single-walled carbon nanotubes exhibit limited transport in soil columns. Environmental Science and Technology 43 (24), 9161-9166.

Johnson, A.C. and Park, B., 2012. Predicting contamination by the fuel additive cerium oxide engineered nanoparticles within the United Kingdom and the associated risks. Environmental Toxicology and Chemistry.

Ju-Nam, Y. and Lead, J.R., 2008. Manufactured nanoparticles: An overview of their chemistry, interactions and potential environmental implications. Science of the Total Environment 400 (1-3), 396-414.

Keller, A.A., Wang, H., Zhou, D., Lenihan, H.S., Cherr, G., Cardinale, B.J., Miller, R. and Zhaoxia, J.I., 2010. Stability and aggregation of metal oxide nanoparticles in natural aqueous matrices. Environmental Science and Technology 44 (6), 1962-1967.

Klaine, S.J., Alvarez, P.J.J., Batley, G.E., Fernandes, T.F., Handy, R.D., Lyon, D.Y., Mahendra, S., McLaughlin, M.J. and Lead, J.R., 2008. Nanomaterials in the environment: Behavior, fate, bioavailability, and effects. Environmental Toxicology and Chemistry 27 (9), 1825-1851.

Ko, C.H. and Elimelech, M., 2000. The 'shadow effect' in colloid transport and deposition dynamics in granular porous media: Measurements and mechanisms. Environmental Science and Technology 34 (17), 3681-3689.

Kretzschmar, R., Barmettler, K., Grolimund, D., Yan, Y.D., Borkovec, M. and Sticher, H., 1997. Experimental determination of colloid deposition rates and collision efficiencies in natural porous media. Water Resources Research 33 (5), 1129-1137.

Kretzschmar, R., Robarge, W.P. and Amoozegar, A., 1994. Filter efficiency of three saprolites for natural clay and iron oxide colloids. Environmental Science and Technology 28 (11), 1907-1915.

Li, K., Zhang, W., Huang, Y. and Chen, Y., 2011a. Aggregation kinetics of $\mathrm{CeO}_{2}$ nanoparticles in $\mathrm{KCl}$ and $\mathrm{CaCl}_{2}$ solutions: Measurements and modeling. Journal of Nanoparticle Research 13 (12), 6483-6491. 
Li, Z., Sahle-Demessie, E., Hassan, A.A. and Sorial, G.A., 2011b. Transport and deposition of $\mathrm{CeO}_{2}$ nanoparticles in water-saturated porous media. Water Research 45 (15), 4409-4418.

Liu, D., Johnson, P.R. and Elimelech, M., 1995. Colloid deposition dynamics in flow through porous media: Role of electrolyte concentration. Environmental Science and Technology 29 (12), 2963-2973.

Liu, X., Chen, G. and Su, C., 2012. Influence of collector surface composition and water chemistry on the deposition of cerium dioxide nanoparticles: QCM-D and column experiment approaches. Environmental Science and Technology 46 (12), 6681-6688.

Liu, X., Wazne, M., Christodoulatos, C., Jasinkiewicz, K.L., 2009. Aggregation and deposition behavior of boron nanoparticles in porous media. Journal of Colloid and Interface Science 330 (1), 90-96.

Navarro, D.A.G., Watson, D.F., Aga, D.S. and Banerjee, S., 2009. Natural organic matter-mediated phase transfer of quantum dots in the aquatic environment. Environmental Science and Technology 43 (3), 677-682.

Pelley, A.J. and Tufenkji, N., 2008. Effect of particle size and natural organic matter on the migration of nano- and microscale latex particles in saturated porous media Journal of Colloid and Interface Science 321 (1), 74-83.

Petosa, A.R., Brennan, S.J., Rajput, F. and Tufenkji, N., 2012. Transport of two metal oxide nanoparticles in saturated granular porous media: Role of water chemistry and particle coating. Water Research 46 (4), 1273-1285.

Petosa, A.R., Jaisi, D.P., Quevedo, I.R., Elimelech, M. and Tufenkji, N., 2010. Aggregation and deposition of engineered nanomaterials in aquatic environments: Role of physicochemical interactions. Environmental Science and Technology 44 (17), 6532-6549.

Quevedo, I.R. and Tufenkji, N., 2012. Mobility of functionalized quantum dots and a model polystyrene nanoparticle in saturated quartz sand and loamy sand. Environmental Science and Technology 46 (8), 4449-4457.

Ryan, J.N. and Elimelech, M., 1996. Colloid mobilization and transport in groundwater. Colloids and Surfaces A: Physicochemical and Engineering Aspects 107, 1-56.

Sarkar, D. and Somasundaran, P., 2004. Conformational dynamics of poly (acrylic acid). A study using surface plasmon resonance spectroscopy. Langmuir 20 (11), 4657-4664.

Shen, C., Huang, Y., Li, B. and Jin, Y., 2008. Effects of solution chemistry on straining of colloids in porous media under unfavorable conditions. Water Resources Research 44 (W05419), 1-12.

Sposito, G., 1989. The Chemistry of Soils, Oxford University Press, Inc., New York.

Tufenkji, N. and Elimelech, M., 2004. Correlation equation for predicting single-collector efficiency in physicochemical filtration in saturated porous media. Environmental Science and Technology 38 (2), 529-536. 
Tufenkji, N., Miller, G.F., Ryan, J.N., Harvey, R.W. and Elimelech, M., 2004. Transport of Cryptosporidium oocysts in porous media: Role of straining and physicochemical filtration. Environmental Science and Technology 38 (22), 5932-5938.

Turro, N.J. and Arora, K.S., 1986. Pyrene as a photophysical probe for intermolecular interactions of water-soluble polymers in dilute solutions. Polymer 27 (5), 783-796.

Van Hoecke, K., De Schamphelaere, K.A.C., Van der Meeren, P., Smagghe, G. and Janssen, C.R., 2011.

Aggregation and ecotoxicity of $\mathrm{CeO}_{2}$ nanoparticles in synthetic and natural waters with variable $\mathrm{pH}$, organic matter concentration and ionic strength. Environmental Pollution 159 (4), 970-976.

Verwey, E.J.W. and Overbeek, J.T.G., 1948. Theory of the Stability of Lyophobic Colloids, Elsevier, Amsterdam.

Wiesner, M.R. and Bottero, J.-Y., 2007. Environmental Nanotechnology, The McGraw-Hill Companies, New York.

Yao, K.M., Habibian, M.T. and O'Melia, C.R., 1971. Water and waste water filtration: Concepts and applications. Environmental Science and Technology 5 (11), 1105-1112. 


\section{Graphical Abstract}

Transport Potential of PAA-coated $n \mathrm{CeO}_{2}$

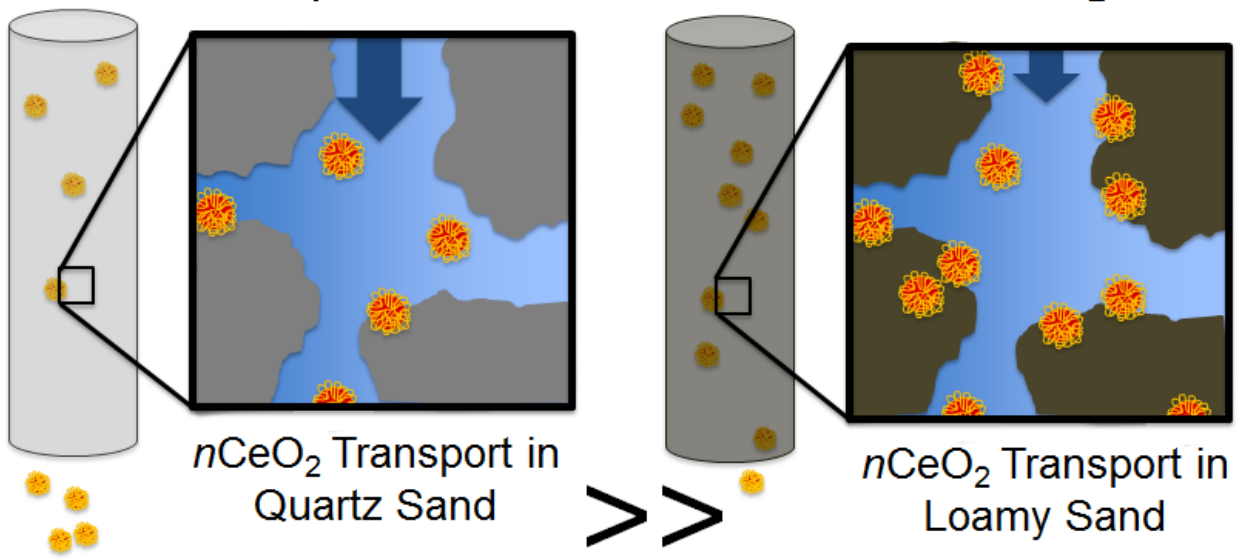

